\title{
PARTICIPAÇÃo POPUlar NOS MARCOS DO CAPITAL: O PROJETO RAÍZES DE CIDADANIA EM QUESTÃo
}

\author{
Evelyne Medeiros Pereira ${ }^{1}$ e \\ Sâmbara Paula Ribeiro ${ }^{2}$
}

\begin{abstract}
Resumo
No presente artigo pretendemos analisar os caminhos da participação popular no Projeto Raízes de Cidadania da Fundação da Criança e da Família Cidadã (FUNCI), instituição da Prefeitura Municipal de Fortaleza, Estado do Ceará, Brasil. Trata-se, assim, da tentativa de desvendar os limites e as possibilidades da participação popular mediatizada pelo poder público local. Na discussão sobre participação, foi necessário um resgate sócio-histórico do processo de constituição da esfera pública e da sociedade civil nos marcos do capital, considerando que os desafios dos processos de participação popular caminham entre as possibilidades de construção de uma "contra-hegemonia popular" e as armadilhas postas numa sociedade que mistifica a realidade e intensifica as relações sociais pautadas na dominação e exploração.
\end{abstract}

Palavras-chave: Participação popular. Sociedade civil. Capital.

\footnotetext{
${ }^{1}$ Mestranda em Serviço Social pela Universidade Federal de Pernambuco (UFPE).

${ }^{2}$ Doutoranda em Serviço Social pela Universidade Federal do Rio de Janeiro (UFRJ) e professora do Curso de Serviço Social da Universidade Estadual do Ceará (UFC).
} 


\section{PopUlar PARTICIPATION WITHIN THE FRAMEWORK OF CAPITAl: The RAÍzES DE CIDADANIA PROJECT IN QUESTION}

\section{Abstract}

In the present article we analyze the forms of popular participation in the Raizes de Cidadania Project of the Foundation of the Child and Family Citizen (FUNCI), an initiative of the Municipality of Fortaleza, state of Ceará, Brazil. This is an attempt to unmask the limits and the possibilities of popular participation mediated by local government. In our discussion of participation, we found it necessary to undertake a socio-historical review of the process by which the public sphere and civil society have been constituted under capitalism, considering that the challenges of the process of popular participation must find a path between the possibilities of constructing a "popular counter-hegemony" and the pitfalls of a society that mystifies the reality and intensifies social relations based on domination and exploitation.

Keywords: Popular participation. Civil society. Capital.

E

ste artigo tem como base um processo investigativo que objetivou problematizar a concreticidade e o discurso vigente em torno da participação popular na atual configuração societária, mais precisamente no município de Fortaleza. Para tanto, foi necessário realizar um resgate histórico do processo de constituição do Estado e da Sociedade civil nos marcos do capitalismo a fim de perceber como a relação entre estas esferas tem recaído sobre o processo de participação popular em âmbito local.

Assim, a pesquisa foi desenvolvida tendo como foco o contexto do Projeto Raízes de Cidadania, que tem como objetivo fomentar a mobilização e participação popular nas comunidades da capital do Ceará. Trata-se de um projeto da Fundação da Criança e da Família Cidadã (FUNCI), órgão da prefeitura municipal de Fortaleza, que a partir de 2005 passa a ser reconfigurado conforme as diretrizes da gestão municipal com representação político-administrativa do Partido dos Trabalhadores (PT).

A investigação foi realizada com base em estudo analítico de base qualitativa que buscou colher dados e informações suficientes para que, com 0 
suporte teórico, fosse viável o diálogo com a realidade concreta. Os instrumentais utilizados foram: análise documental e entrevista semi-estruturada.

Partindo do universo de vinte e três núcleos do projeto, chamados de Raízes de Cidadania, distribuídos nas seis Secretarias Executivas Regionais ${ }^{3}$ de Fortaleza perfazendo um total de cento e trinta e oito profissionais das áreas de Psicologia (vinte e três), Serviço Social (vinte e três), Direito (vinte e três), Assessoria Comunitária (cinqüenta e um), excluindo os nove coordenadores do projeto ${ }^{4}$, foi necessário definir uma amostra de quinze profissionais (10 \%) com atuação nas áreas de Serviço Social e Assessoria Comunitária ${ }^{5}$ em diferentes bairros. Vale ressaltar que um dos critérios de escolha desta amostra foi o recorte de gênero sendo contemplado proporcionalmente nas entrevistas pessoas do sexo feminino e masculino.

As entrevistas foram realizadas no período correspondente aos meses de fevereiro e março de 2007. Além das entrevistas colhidas, as informações contidas nos documentos Projeto Raízes de Cidadania e Manual de Organização do Projeto Raizes de Cidadania foram fundamentais para a disposição de elementos básicos que viabilizaram esta pesquisa.

Acreditamos que a relevância deste estudo está no fato de potencializar reflexões que possam contribuir para as análises e práticas contemporâneas orientadas para o desencadeamento de reais processos de participação popular. É importante lembrar que os resultados desta investigação representam uma tentativa de aproximação da realidade que é, portanto, histórica e processual.

\footnotetext{
${ }^{3}$ A divisão da estrutura administrativa de Fortaleza em seis micro-regiões (Secretarias Executivas Regionais) foi realizada mediante reforma administrativa ocorrida durante gestão municipal de Juraci Magalhães (PMDB).

${ }^{4}$ Dados do documento Projeto Raízes de Cidadania de Março de 2007.

${ }^{5}$ Áreas mais afins aos interesses da pesquisa tendo em vista que, no caso mais específico dos assessores comunitários, são profissionais que deveriam estar mais próximos do cotidiano comunitário, pois muitos deles são moradores dos bairros em que trabalham.

${ }^{6}$ Com intuito de preservar a identidade dos profissionais, durante as entrevistas, os nomes de cada um foram substituídos por características pessoais dadas pelos próprios entrevistados, além da profissão ou cargo que ocupavam.
} 


\section{Participação ou Passivização ${ }^{7}$ Popular?}

Parte-se de uma compreensão sobre participação enquanto um processo de ação/reflexão historicamente construído pelas classes subalternas, o que respalda a adjetivaçãopopular.

0 intuito é atentar para as formas com que esta participação vem sendo concretizada diante da lógica de alienação alicerçada pela estrutura de exploração do trabalho alienado ${ }^{8}$ que exige uma parcialidade e conformismo daqueles que vendem sua força de trabalho. Desta forma, pode-se referir a participação

enquanto forma de intervenção crítica das classes subalternas no movimento histórico, efetivada na contracorrente dos processos ideológicos subalternizantes. Assim, coloca-se também como instrumento estratégico do processo de politização das relações sociais e da elaboração e afirmação, por essas classes (subalternas), de uma vontade coletiva (ABREU, 2002, p. 187).

A participação popular, nesta ótica, vem caminhando entre as possibilidades e os limites postos pelas contradições da sociedade do capital. Dentre as possibilidades, a de funcionar como "potencializadora" do desenvolvimento da autonomia dos sujeitos sociais "subalternizados" que demanda necessariamente a tomada de consciência, o processo de catarse', e a intervenção dessa classe no movimento histórico na perspectiva de sua emancipação.

0 desencadeamento desse processo demanda mediações indispensáveis para o desenvolvimento de uma consciência crítica e de um processo emancipatório favorável à constituição da hegemonia orientada pela "classe-que-vive-dotrabalho"10.

\footnotetext{
${ }^{7}$ Termo utilizado por Edmundo Dias (1997) referenciando a naturalização e "des-historicização" da vida social.

${ }^{8} 0$ trabalhador torna-se uma mercadoria tanto mais barata, quanto maior número de bens produz (...) 0 trabalho não produz apenas mercadorias; produz também a si mesmo e ao trabalhador como uma mercadoria, justamente na mesma proporção com que produz bens. A realização do trabalho aparece na esfera da economia política como desrealização do trabalhador, a objetivação como perda e servidão do objeto, a apropriação como alienação (MARX, 2004, p. 111-112).

${ }^{9}$ Segundo Portelli, a concepção gramsciana de catarse é caracterizada como sendo o momento de tomada de consciência positiva, fase na qual as ideologias que germinam anteriormente tornam-se "partido", confrontam-se e entram em luta. 0 processo de catarse relaciona-se, portanto, com a desnaturalização das injustiças sociais (1977, p.63).
}

${ }^{10}$ Ver em Antunes (2003). 
0 desenrolar histórico dos caminhos da participação popular nos marcos da sociabilidade do capital aponta a relação Estado - Sociedade civil como eixo fundamental das experiências passadas e em curso. Esta relação vem, portanto, refletindo o movimento dialético das forças sociais frente a uma realidade de intensificação da questão social ${ }^{11}$ advinda da estrutura capitalista peculiar a cada período histórico.

Assim, toma-se por base a análise da sociedade política e da sociedade civil enquanto esferas vinculadas organicamente e, portanto, fundamentais para a construção e manutenção da hegemonia. As configurações da relação entre essas esferas são orientadas pelo campo de contradições postas na realidade movidas por interesses e projetos antagônicos das classes sociais. Por isso, os rumos da participação popular têm como característica fundamental os conflitos sociais que podem, ou não, favorecer sua ampliação.

Quanto mais organizada e fortalecida a sociedade civil, do ponto de vista das classes subalternas, ampliam-se as possibilidades de participação popular, ou seja, há um campo mais ampliado para construção de uma contra-hegemonia formada em torno de interesses coletivos (e universais) através da construção de um novo bloco bistórico ${ }^{12}$. Assim, as (re) configurações da relação sociedade civil/sociedade política são impulsionadas pela correlação de forças (sociais) que podem, ou não, fomentar a participação das camadas desprivilegiadas na ordem capitalista.

Diante das reflexões conceituais em torno da participação popular desenvolvidas até então, mesmo diante do campo de possibilidades mencionadas acima, torna-se necessário retomar algumas questões referentes aos limites estruturais postos na sociedade capitalista que castram toda e qualquer experiência que objetive a concretização plena do processo de participação. As possibilidades esbarram em uma estrutura organizativa (política, econômica, social e cultural) multifacetada de dominação e exploração de classe que aliena. Há, portanto, nos marcos do capitalismo, obstáculos que dificultam o conjunto de trabalhadores a exercerem hegemonia no capitalismo.

\footnotetext{
${ }^{11}$ Questão social apreendida como o conjunto das expressões das desigualdades da sociedade capitalista madura, que tem raiz comum: a produção social é cada vez mais coletiva, o trabalho torna-se mais amplamente social, enquanto a apropriação dos seus frutos mantém-se privada, monopolizada por uma parte da sociedade (IAMAMOTO, 2000, p. 27-28).
}

${ }^{12}$ Ver em Portelli (2002). 
Assim, a participação popular deve ser compreendida enquanto um instrumento estratégico da classe trabalhadora que não finda em si mesmo, mas que deve ter como eixo norteador a transformação social, a construção de outra sociabilidade. Desta forma, as experiências participativas voltadas para os interesses das classes subalternas devem atingir os aspectos fundamentais da organização da produção e do orçamento e financiamento público. Caso contrário, as experiências concretas de participação popular serão apropriadas e aprimoradas como mecanismos de "passivização" em prol da acumulação do capital e exploração dos trabalhadores por parte de uma parcela cada vez menor da humanidade.

\section{CAMINHOS HISTÓRICOS DA PARTICIPAÇÃO POPULAR}

0 processo histórico demonstra que as lutas sociais e populares têm sido formas importantes de participação popular, além de impulsionar a construção e conquista de espaços que propiciem o seu exercício, como instrumento pedagógico de aprendizado e de socialização do poder (econômico e político) que, no entanto, só poderá ocorrer em sua plenitude em outra sociabilidade (NETTO, 1990).

Algumas dessas conquistas estão inseridas no âmbito democrático (democracia participativa) e permitem a constituição de espaços "institucionalizados" de participação popular, muito relevante no cenário contemporâneo. Trata-se de instâncias descentralizadas de participação conselhos, fóruns, conferências, etc. - ligadas diretamente ao Estado com 0 intuito de "democratizar" a esfera pública, onde os setores organizados da sociedade civil possam participar da fiscalização e planejamento da gestão das políticas públicas, entre outras ações estatais (orçamento público, plano diretor, etc.). Essa forma de participação tem sido bastante relevante em administrações públicas caracterizadas como democráticas e populares nos últimos anos, sendo hegemonicamente associada ao processo de consolidação da cidadania.

0 capitalismo, em suas constantes crises, constrói mecanismos de dominação que atingem as condições de existência (objetiva e subjetiva) da classe trabalhadora, no intuito de manter sua hegemonia. Na realidade latino-americana, por exemplo, mais especificamente a partir da década de 1950 com a ascensão de políticas modernizadoras, toma força junto ao modelo desenvolvimentista um discurso em torno da "participação popular" nos programas de governos como forma de incentivar processos de "integração" e "promoção" sociais (ABREU, 
2002). Na verdade, o objetivo dos governos, influenciados diretamente pelas organizações internacionais como a Organização das Nações Unidas (ONU), era de construir uma base de apoio popular frente às mudanças estruturais impostas pelo padrão emergente de acumulação e reprodução do capital. Além disso, havia a necessidade de conter a "ameaça comunista", pois representava um entrave ao modelo de desenvolvimento implantado no país.

Por isso, o forte apelo à "participação popular" - reafirmado, posteriormente, durante a ditadura militar - acompanhado pela disseminação da ideologia da "resignação" e do "conformismo" respaldando a idéia de que o novo ciclo de desenvolvimento beneficiaria toda a coletividade.

Nos anos de 1960, a realidade brasileira era caracterizada pela inflação desordenada, redução do crescimento econômico e endividamento externo, reflexo de uma crise mundial do conhecido Welfare State. Nesse momento, há ascensão de intensa mobilização de setores progressistas que fortaleceu uma consciência nacional-popular (ABREU, 2002) impulsionando a luta por "reformas de base". As experiências de participação popular ${ }^{13}$, em evidência nesse período, apresentam como característica central a politização dos setores populares.

No entanto, essas iniciativas foram duramente reprimidas pelo Golpe Militar de 1964 que forneceu as bases para a ascensão de um regime autoritário que duraria mais de 15 anos. Neste período, há a renovação de mecanismos de incentivo à "participação popular", associada à integração social. Uma participação mistificada por programas sociais ${ }^{14}$, instrumentos de manutenção da "ordem" social vigente. Sob a ideologia funcionalista, a participação popular passa a ser trabalhada como instrumento de adesão e consentimento da população legitimando uma estrutura concentradora de poder e renda.

Os focos de resistências construídos em toda América Latina, a partir da década de 1970, impulsionaram, no Brasil, o processo de "democratização"

\footnotetext{
${ }^{13}$ Entre outros, as Ligas Camponesas, o Movimento de Educação de Base (MEB), os movimentos de promoção da cultura popular - a exemplo dos Centros Populares de Cultura (CPCs) ligados a União Nacional dos Estudantes (UNE) e do Movimento de Cultura Popular (MCP) (ABREU, 2000, p. 113).

${ }^{14}$ Dentre estes, incluem-se: Programa de Integração Social (PIS), Movimento Brasileiro de Alfabetização (Mobral), Programa Nacional de Centros Sociais Urbanos (CSUs), entre outros que tinham como eixo central a "participação popular" como fator de integração e promoção social. (ABREU, 2002)
} 
do Estado Brasileiro durante a década de 1980, cenário de crise de legitimidade política e de intervenção das classes populares no movimento histórico através de experiências organizativas (a exemplo das práticas associativistas) em torno de bandeiras democráticas, contra o sistema autoritário e rigidamente hierarquizado.

No entanto, há que ressaltar o seguinte:

Os anos 80 na sociedade brasileira são marcados por um verdadeiro paradoxo engendrado, por um lado, pela onda democratizante cuja culminância é a aprovação de uma Constituição Federal/1988, a partir de um processo que envolveu a participação de vários segmentos organizados da sociedade e incorporou sob a forma de direitos sociais garantidos pelo Estado grandes bandeiras de luta das classes subalternas; e, por outro, como imposição dos órgãos de financiamento internacional, a redução dos gastos públicos no âmbito das políticas sociais direcionadas ao atendimento das necessidades de reprodução das classes subalternas, sem prejuízo, é claro, do financiamento público da reprodução do capital (ABREU, 2002, p.151).

Com a ascensão da crise do capital desencadeada pelo esgotamento do padrão fordista-keynesiano ${ }^{15}$ que se acentua no Brasil, principalmente, na década de 1990, com a consolidação do neoliberalismo, há uma imposição pelos países capitalistas centrais de ajustes macroeconômicos e reformas institucionais, além da reestruturação nos processos produtivos conforme demanda o padrão de acumulação flexível em ascensão.

$\mathrm{Na}$ verdade, esses ajustes representam um conjunto de medidas "anticrise" que incidem sobre toda a sociedade, respaldado por uma nova racionalidade que, conforme sinaliza Abreu (2002), investe decisivamente na desmobilização e esvaziamento das lutas sociais, mediante, sobretudo, a busca de soluções negociadas entre empresariado e trabalhadores. Percebe-se, nesse momento, a ascensão do discurso em prol do envolvimento popular na implementação das políticas sociais visando não apenas a legitimidade do novo governo, mas a própria institucionalização do trabalho comunitário como alternativa para redução dos custos no âmbito das políticas sociais.

Segundo Simionatto (2001), reaparece o novo (velho) discurso sobre o controle da pobreza e participação popular revestido pelo ideário "neoliberal modernizado" que clama pela minimização do Estado e pela responsabilização da sociedade para com a questão social através da política de parceria entre 0 setor público e o privado.

${ }^{15}$ Ver Antunes (2003). 
Este discurso faz-se presente nos programas e projetos de organismos internacionais (Organização das Nações Unidas/ONU, Banco Interamericano de Desenvolvimento/BIRD, Banco Mundial, entre outros.) que impulsionam a efetivação de propostas de ajustes neoliberais. Trata-se de um mecanismo ideológico que encobre questões estruturais advindas do conflito entre capital e trabalho e funciona como verdadeiro amortecedor dos conflitos sociais que poderiam emergir como maior força diante de uma conjuntura de retirada de direitos historicamente conquistados, intensificação da exploração capitalista e aumento das desigualdades sociais.

Neste sentido, o discurso "fetichizado" da participação passa a ter papel fundamental para legitimar essa "nova" racionalidade. Esse discurso desloca a questão social do campo da política econômica para a participação da sociedade civil, imputando a esta a responsabilidade no atendimento às demandas dos trabalhadores, o que respalda o processo de privatização da esfera pública, estimulando o colaboracionismo, estratégia para a constituição das novas relações produtivas do processo de acumulação em curso (SIMIONATTO, 2006). Vale ressaltar a relevância de uma concepção liberal acerca da sociedade civil que passa a ser consolidada enquanto um conjunto homogêneo de "atores sociais".

As consequiências desse processo recaem sobre as organizações coletivas das classes subalternas que se fragilizam frente ao ciclo expansivo de mundialização capitalista que intensifica a exploração e produz condições de vida cada vez mais precárias para aqueles que vivem do trabalho. Com isso, há uma crescente despolitização da sociedade civil que contribui para uma correlação de forças desfavorável para construção de uma contra-hegemonia em torno de um projeto societário de emancipação humana.

\section{A PARTICIPAÇÃO NO CONTEXTO LOCAL DO MUNICÍPIO DE FoRTALEZA}

A história de Fortalezaémarcada por um processo crescente de concentração demográfica, decorrente do fluxo migratório que vem se intensificando devido a alguns fatores. Dentre estes, a rígida estrutura fundiária do estado, alicerçada por uma forte concentração de terras e a falta de políticas públicas que possam garantir a permanência no campo para as populações do interior cearense que, sem expectativa de vida, historicamente vêm se deslocando para a capital, principalmente, durante os fortes períodos de estiagem. 
A construção do tecido social de Fortaleza é caracterizada por uma forte segregação social que acompanha a formação da cidade e tem como característica central a profunda desigualdade em que a maioria da população é desprovida de atenção do Estado e, por isso, não tem acesso aos meios de consumo coletivo, bem como dignas condições de sobrevivência na realidade urbana.

Tomando como referencia o contexto da década de 1970, percebe-se a organização das classes subalternas de Fortaleza que passam a buscar formas de enfrentamento à questão social pressionando o poder público para melhores condições de vida em vários bairros ${ }^{16}$ da capital cearense. Por outro lado, os gestores do Estado, munidos de um conjunto de medidas de controle, passam a desmobilizar as organizações das camadas populares.

Neste período, ascende o discurso de modernização do Estado tomando relevância o grupo de jovens empresários - AJE (Associação dos Jovens Empresários) - ligados ao CIC (Centro Industrial do Ceará). Trata-se de uma elite empresarial que passa a ganhar legitimidade popular buscando intensificar a lógica de acumulação do capital no contexto local através da disseminação do ideário neoliberal. Esse processo cria condições favoráveis para que, em 1986, nas eleições para governo estadual, esse grupo chegue ao poder político-administrativo do Ceará dando origem ao que passou a se denominar "governo das mudanças" ${ }^{17}$ que, segundo Teixeira (1995), representa uma vanguarda do neoliberalismo no Brasil.

Durante a década de 1980, o contexto político fortalezense é marcado por uma correlação de forças favoráveis a intensas mobilizações e organizações populares $^{18}$ que impulsionaram a ascensão do Partido dos Trabalhadores (PT)

\footnotetext{
${ }^{16}$ Conforme Barreira (1992), os bairros passam a ter visibilidade política e organizativa das classes subalternas, configurando como espaços significativos dos conflitos de classe na cidade. Esses conflitos evidenciam a lógica capitalista dos grupos econômicos locais, que tem na especulação imobiliária uma das principais formas de acumulação.

${ }^{17}$ Segundo Teixeira (1995), o grupo do CIC, encabeçado por Tasso Jereissati, apresenta como principais medidas "mudancistas" para o "crescimento econômico": o enxugamento da máquina estatal e mudanças na estrutura produtiva econômica através da criação de várias empresas para o possível aumento de postos de trabalho. 0 que, na verdade, houve foi um aumento considerável da taxa de desemprego ( $10 \%$ da força de trabalho) além da elevação da concentração de renda nas mãos dos mais ricos.

${ }^{18}$ Nos anos 80, a Frente Sindical dos Trabalhadores Rurais e Urbanos do Ceará é fundada, contribuindo posteriormente, para a construção da Central Única dos Trabalhadores - CUT. Essa
} 
ao governo municipal nas eleições 1985. Esse processo representa um marco na história política da cidade e do estado caracterizado pela predominância do coronelismo e de suas práticas clientelistas.

A esfera político-administrativa municipal, apoiada por movimentos e entidades populares, desenvolve ações próprias do que passa a ser denominado de "administração popular" que, no entanto, logo, é atacada pelas forças conservadoras da época. Dentre estas, aquelas ligadas ao grupo do CIC, do governo do Estado, que não tardaram a fazer alianças inviabilizando a gestão do PT. 0 grupo passa, então, a assumir a gestão municipal a partir das eleições ${ }^{19}$ seguintes dando início ao modelo político-administrativo consolidado na cidade nos últimos quatorze anos.

Nessa perspectiva, com o intuito de manipular, cooptar e desarticular as lutas sociais e organizações dos bairros ${ }^{20}$, os aparatos estatais passam a utilizar estratégias de incentivo a institucionalização dessas organizações atrelandoas a gerência de políticas públicas. Desta forma, multiplicam-se as associações comunitárias como forma de acesso aos programas sociais.

Assim, a passagem do caráter "contestador" das organizações das classes subalternas para uma perspectiva "colaboracionista" está inserida na nova configuração da relação entre Estado e Sociedade Civil, demandada pela crise do capitalismo. 0 arrefecimento das lutas sociais, o atrelamento à burocracia estatal e a perca da força de enfrentamento e resistência são características de uma realidade complexa influenciada por transformações políticas, econômicas e sociais em escala mundial na década de 1990.

As mudanças ocorridas em Fortaleza, desde então, aceleram o processo de pauperização da maioria da população. A cidade, contraditoriamente, se torna um

década também é caracterizada pela consolidação e atuação da Federação de Bairros e Favelas, fortalecendo a formação dos conselhos de bairros e associações, contribuindo para a dinâmica organizativa dos setores populares.

${ }^{19}$ Nestas eleições, houve a vitória de Ciro Gomes pelo Partido do Movimento Democrático Brasileiro (PMDB). Com a elevação deste ao cargo de governador do Estado pelo Partido da Social Democracia Brasileira (PSDB) - sucessor de Tasso - em 1989, o vice-prefeito de Fortaleza, Juraci Magalhães, assume a prefeitura pela sigla do PMDB.

${ }^{20}$ Programas de governo como, o Agentes de Mudanças, durante a gestão do Partido Social Democrata Brasileiro (PSDB), e, posteriormente, a criação do Centro de Capacitação de Lideranças favoreceram o processo de cooptação das organizações políticas e infiltração da ideologia governista nos movimentos sociais. 
moderno símbolo do turismo empresarial. Historicamente a construção da cidade de Fortaleza é marcada por uma relação estreita entre poder público e especulação imobiliária em que grupos empresariais (locais e internacionais) influenciam diretamente nas prioridades para o orçamento da cidade.

Merecedestaque, nosúltimos anos, a crise de legitimidade dasforças políticas tradicionais na gestão municipal da cidade representadas pela administração do PMDB que estava há mais de 15 anos à frente da prefeitura municipal. Esta conjuntura local contribuiu para a ascensão do Partido dos Trabalhadores (PT) no cenário político tendo como marco as eleições municipais de $2004^{21}$. Isto não seria possível sem o envolvimento e o apoio de diversos setores populares, sindicais e estudantis do campo da esquerda política na campanha eleitoral ${ }^{22}$.

0 programa de governo apresentado à sociedade fortalezense passa a ter como elemento central a necessidade de construir uma gestão pública democrática e popular. No entanto, é importante evidenciar que, mesmo adotando algumas políticas de incentivo a participação popular através de iniciativas como o Plano Plurianual Participativo (PPP), Orçamento Participativo (OP) e Plano Diretor Participativo (PDP), a gestão municipal vem dando continuidade a uma política pragmática através de acordos com a elite econômica (empresas do setor de transporte, por exemplo) e parcerias publico - privado (ONGs, Banco Mundial, etc.) cedendo aos ajustes neoliberais.

A capital, hoje, com cerca de 2.416.92023 habitantes e composta por 114 bairros oficialmente reconhecidos ${ }^{24}$, apresenta uma realidade caótica de crise estrutural, reflexo de um contingente de transformações ocorridas nos últimos trinta anos nos centros urbanos. Há, portanto, um processo em curso, marcado pela expansão das "áreas de risco" e favelas na cidade, motivado, principalmente, pela

\footnotetext{
${ }^{21}$ Nesse momento, a prefeitura passa a ter como representante Luizianne Lins do PT.

${ }^{22}$ A conjuntura eleitoral de 2004 favoreceu o desencadeamento de novos processos organizativos das forças políticas e populares. Logo depois das eleições, através de assembléias e plenárias em diversos bairros e comunidades da cidade, é fundado o Movimento dos Conselhos Populares (MCP) que atualmente assumisse uma postura autônoma e de reivindicação em relação à administração pública da cidade.

${ }^{23}$ Disponível em www.ibge.org.br, Março de 2007.

${ }^{24}$ Segundo o documento Projeto Raízes de Cidadania (2007), destes bairros, apenas sete apresentam índice de desenvolvimento humano (IDH) alto, tendo a maioria, 66 bairros, índice considerado médio e 41 bairros com baixo IDH.
} 
falta de planejamento urbano, intensa especulação imobiliária e permanência do modelo de agricultura excludente no estado que contribui para as más condições de vida da população do campo que migra para a capital. Toma evidência a contínua elevação dos índices de pobreza, desigualdade social, concentração de renda e desemprego.

\section{RAÍZES DE CIDADANIA: RUMO A QUAL PROJETO DEMOCRÁTICO E POPULAR?}

Em 1993, a Prefeitura de Fortaleza, na administração do PMDB, cria a Fundação da Criança da Cidade (FUNCI) através da lei nº 7.488 com o intuito de dar respostas às problemáticas sociais no âmbito da criança e do adolescente, um dos segmentos mais atingidos pelo quadro de crise estrutural que vem repercutindo na cidade. Esse órgão foi pensado enquanto personalidade jurídica de direito público, dotada de autonomia financeiro-administrativa e patrimonial (RIBEIR0, 2000) vinculado à Secretaria do Trabalho e da Ação Social do Município (STAS), hoje Secretaria Municipal de Assistência Social (SEMAS).

Segundo Ribeiro (2000), a FUNCI, responsável pelo desenvolvimento da política voltada à criança e adolescente em todo o município, tem no seu discurso oficial a participação da sociedade na co-gestão de programas e projetos implementados através do estabelecimento de parcerias.

Dentre um conjunto de mudanças na estrutura organizacional, em 1996, é implantado o projeto Agências de Cidadania que, segundo o documento Projeto Raizes de Cidadania (2007), funcionava como um serviço de atendimento social, jurídico e psicológico voltado, principalmente, às familias das crianças e adolescentes participantes de projetos da Fundação para ampliar as ações voltadas para 0 atendimento de crianças e adolescentes e suas famílias.

Em 1999, através da Lei 8.389, essa instituição - FUNCI - passa a se chamar Fundação da Criança e da Família Cidadã com a justificativa de ampliação de seus objetivos e atividades. A perspectiva preventiva e educativa passa a ser a linha de atuação prioritária dos programas e projetos.

Com as mudanças ocorridas na capital a partir do período eleitoral de 2004, que viabilizaram a ascensão do PT no cenário político-administrativo do município, a Fundação passa por um processo de reestruturação e adota uma 
nova linha de açã $0^{25}$ com o objetivo de promover e garantir direitos humanospara e com crianças e adolescentes.

É importante observar a continuidade na política de parcerias, prioritariamente com organizações não-governamentais (ONGs), mediante recursos advindos, principalmente, do Fundo de Direitos da Criança e do Adolescente, criado com base no Estatuto da Criança e do Adolescente (ECA).

Com vistas a cumprir as metas da nova administração pública local, que assume a tarefa de aprofundar o processo de municipalização como forma de descentralizar e democratizar a esfera pública, a Fundação passa a priorizar iniciativas de caráter "participativo e popular". Dentre estas, o Projeto Raízes de Cidadania, que em 2005 é constituído - a partir de um redirecionamento do projeto Agências de Cidadania, existente desde 1996 - apontando para uma atuação respaldada na

constituição de objetivos voltados à autonomia comunitária e fortalecimento de uma atuação interdisciplinar e dialógica. É nesta perspectiva que as raízes de cidadania assumem um espaço de articulação da rede comunitária e de políticas públicas. (PROJETO RAÍZES DE CIDADANIA, 2007)

Desta forma, o projeto apresenta elementos, do ponto de vista teórico, conjugados diretamente com a nova diretriz político-pedagógica da Fundação. Segundo os documentos oficiais, o projeto tem o intuito de fortalecer as redes comunitárias por intermédio das parcerias com outros programas e projetos da FUNCI, além de outras instituições e entidades (associações, ONGs, instituições filantrópicas, etc.) de caráter público e/ou privado presentes no cotidiano das comunidades atendidas pelo projeto.

Termos como emancipação comunitária e cidadania passam a ser freqüentes no vocabulário, documentos e capacitações do projeto que está organizado em vinte e três núcleos formados por equipes multidisciplinares ${ }^{26}$ divididas no mesmo número de bairros no município de Fortaleza.

Convém destacar que o objetivo geral do projeto é

\footnotetext{
${ }^{25}$ Esta linha de ação é fundamentada nos seguintes eixos: Família, arte - educação, cidadania e qualidade de vida, com foco em gênero e sócioeconomia solidária.

${ }^{26}$ Cada equipe é composta por um profissional das seguintes áreas: Psicologia, Serviço Social, Direito e Assessoria Comunitária. Os assessores comunitários são profissionais, em sua maioria, moradores das proximidades dos bairros onde o Projeto funciona e, por isso, inseridos nas dinâmicas sócio-históricas das comunidades.
} 
contribuir para o funcionamento de uma rede articulada de ações jurídicopsico-sociais junto às comunidades, visando integrá-las às políticas públicas para crianças, adolescentes e suas famílias através da construção e potencialização de processos de emancipação e autonomia pessoal e comunitária (MANUAL DE ORGANIZAÇÃO DO PROJETO RAÍZES DE CIDADANIA, 2006).

Assim, os documentos dispõem que as atividades desenvolvidas pelo projeto devem ser planejadas e executadas em conjunto com a comunidade tendo a realização dos Fóruns Comunitários Locais ${ }^{27}$ como atividade obrigatória. Daí a fundamental importância da participação popular nas ações do projeto.

\section{Os LIMITES E POSSIBILIDADES DA PARTICIPAÇÃO popular mediante o Projeto Raízes de Cidadania}

Mediante as análises dos documentos oficiais e depoimentos de profissionais, percebe-se que a proposta de intervenção do projeto, orientada para a organização, mobilização e educação popular, apresenta fragilidade e inconsistência. Isso acaba por prejudicar o desenvolvimento de ações direcionadas para a efetivação de processos coletivos em torno dos reais interesses e anseios das classes subalternas.

Nota-se que, em muitos casos, o Projeto acaba sendo utilizado como mecanismo eficiente de instrumentalização da população para legitimar processos já concebidos em prol do alcance das metas estabelecidas pela política da gestão municipal.

Há um discurso bastante enfático em torno do estabelecimento de parcerias que, segundo o Projeto Raízes de Cidadania (2007), deve funcionar como estratégia de superação de limites e busca pela efetivação de direitos, tendo por princípios a sustentabilidade das ações, a co-responsabilidade e a autonomia da comunidade. Portanto, a perspectiva é de que as parcerias estão em consonância com o processo de construção da cidadania.

A referência à autonomia comunitária possui centralidade nos documentos e alguns depoimentos dos profissionais do Projeto. Porém, as reflexões

\footnotetext{
${ }^{27}$ Esses fóruns ocorrem semestralmente e devem ser realizados nos bairros onde existem as raízes. 0 objetivo é construir um espaço de debate entre poder público e sociedade civil com 0 intuito de fomentar a participação popular no projeto de forma a consolidar parcerias durante 0 planejamento, a execução e avaliação das atividades do Projeto.
} 
destes parecem caminhar para ações de caráter neoliberal, impulsionando 0 processo de desresponsabilização das funções do Estado para com as políticas públicas.

Sobre este assunto, Coraggio (1994) ressalta que a atual configuração da relação entre Estado e sociedade civil é marcada pela volta, sob novas bases, às sociedades de beneficência, para controlar as possíveis explosões dos mais afetados por este processo de globalização do poder. Se vier acompanhado de discursos como "não dar o peixe, mas ensinar a pescar" e "não resolver os problemas, mas passar responsabilidade aos próprios prejudicados", isto não muda seu real alcance, que se torna claro quando há, por um lado, o caráter maciço da pauperização e a dimensão escassamente paliativa dos recursos comprometidos.

Assim, percebe-se a consonância das falas abaixo com a perspectiva descrita acima:

As parcerias - com entidades, lideranças, equipamentos sociais, etc. - têm sido fundamental. Hoje, pra se trabalhar nas comunidades em um projeto como o nosso subsidiado pela prefeitura, com todas suas dificuldades, 0 trabalho vai funcionar muito bem se a gente for eficiente e formar essas parcerias (...) sabendo que é mais um elo em uma corrente que está crescendo de força real, de cada um carregar um tijolinho mesmo em vez de ficar esperando o caminhão da prefeitura pra tirar aquele entulho, cada um pegar sua pedrinha e tirar. Não ficar anos de braços cruzados esperando vir um caminhão (Idealista/Assessor Comunitário).

Facilitar a comunidade a se organizar (...) facilitar o desenvolvimento social da comunidade (...) Nós não chegamos e entregamos o peixe, mas ensinamos a pescar (Perseverante/Assessor Comunitário).

Há, portanto, um paradoxo presente tanto nas colocações feitas pelos entrevistados como nas diretrizes postas nos documentos do Projeto, pois, ao mesmo tempo em que se enfatiza a necessidade de fortalecimento da esfera pública, ampliação e garantia de direitos por parte do Estado, há um direcionamento para o estabelecimento deparcerias que acabam reforçando o descrédito da ação estatal e legitimando a lógica de responsabilização da sociedade civil pelos agravantes da questão social.

As parcerias são aludidas por alguns dos entrevistados como sendo uma forma eficaz de desenvolver o trabalho nas comunidades diante da dificuldade financeira do Projeto que, inclusive, é colocada pela maioria como sendo uma das principais limitações para o desenvolvimento dos trabalhos. 
Além disso, parte dos depoimentos demonstra a predominância de uma concepção de Estado e Sociedade civil dissociada da concreticidade histórica, pois evocam uma relação de colaboracionismo e cooperação que oculta os conflitos e contradições presentes na égide do capital que, na sua configuração contemporânea, beneficia-se de tal proposta sendo uma estratégia de saída para a crise do Estado:

A relação entre Estado e Sociedade civil deveria ser uma relação de igualdade (...) diálogo (...). Acho que assim diminuiria essa questão de greve, de passeata... Esses negócios que muitas vezes acaba em violência (Tranqüilo/ Assessor Comunitário).

Trata-se de uma concepção em evidência no debate contemporâneo que tende a neutralizar os conflitos sociais em defesa de interesses puramente corporativos e particularistas, bloqueando a constituição de esferas públicas como instâncias em que possam ser confrontados as diferenças e antagonismos de classes, o que contribui para uma dispersão das forças sociais e o enfraquecimento da organização de sujeitos políticos coletivos.

A participação popular assume papel fundamental nas falas dos entrevistados frente à necessidade da democratização da relação entre Estado e Sociedade civil:

Não é só participar por participar, mas participar tendo um objetivo, um direcionamento, uma visão de transformação (...) quando você fala em popular é aquela coisa bem ampla, então, é participação nos movimentos, conselhos, conferencias... (...) participação popular dentro dos grupos que os projetos desenvolvem pra está buscando com que o povo participe e estejam buscando 0 que querem, visando a mudança (...). Não é a questão só de cobrar, mas contribuir para o crescimento da cidade e fortalecimento da cidadania (Dinâmica/Assistente Social).

No entanto, percebe-se a ausência de um referencial, inclusive nos próprios documentos, que apontem para os reais objetivos que se pretende alcançar através da potencialização, por intermédio do Projeto, de experiências de participação popular nas comunidades. Isto tem favorecido a inexistência, na maioria dos depoimentos, de elementos indissociáveis ao processo de participação popular: seu caráter político e classista.

É presente em algumas falas uma concepção de participação popular pautada na ótica desenvolvimentista. Expressões como: "contribuir para o crescimento da cidade" (Dinâmica/Assistente Social), "participar efetivamente 
de sua comunidade fazendo com que ela se desenvolva a partir das suas necessidades" (Perfeccionista/Assessora Comunitária), "participar ativamente do desenvolvimento do seu bairro" (Perseverante/Assessor Comunitário) e "melhorias para a comunidade" (Calma/Assistente Social) acabam sendo relacionadas com o objetivo da participação popular, o que demonstra que ainda persiste, nos trabalhos desenvolvidos pelos profissionais, noções e princípios relacionados à perspectiva curativa (SOUSA, 2000) na tentativa de amenizar as problemáticas sociais.

Há inúmeras contradições presentes no contexto do Projeto, desde a sua fundamentação aos discursos construídos e ações implementadas, uma vez que em nenhum momento se esclarece a concepção de participação popular e, por vezes, se afirma o seu contrário.

Sobre isto, ressalta Abreu (2002) que o momento histórico expõe verdadeiros dilemas para a participação popular tendo em vista as relações contraditórias entre as novas estratégias de controle social do capital e a perspectiva de constituição da contra-hegemonia das classes subalternas.

A maioria dos entrevistados se contradiz quando falam sobre a participação popular no âmbito do Projeto Raízes de Cidadania, pois nas suas próprias reflexões, principalmente em torno do processo de planejamento, execução e avaliação das atividades, acabam demonstrando que a participação dos moradores dos bairros não é tão efetiva como se pretende ser e, por vezes, essa participação parece não ocorrer.

Sempre que a gente pensa em fazer alguma atividade, a gente pensa em trazer o pessoal da comunidade. A gente pensa, primeiro, em formar um grupo. Depois do grupo formado, a gente ver as pessoas, a gente faz o encontro, convida e quando a gente convida as pessoas, a gente pensa em como fazer junto com elas. A gente pensa o que elas gostariam de falar, de conversar, quais as atividades que elas gostariam de participar (Tranqüilo/Assessor Comunitário).

Como demonstra a maioria dos depoimentos, as finalidades e a concepção de participação popular não são claramente definidas pelos profissionais, assim como nos próprios documentos analisados.

Algumas falas responsabilizam as próprias comunidades pelas dificuldades de participação popular no Projeto:

0 processo de mobilização não é fácil. As pessoas são muito acomodadas, 
querem estar sentadas recebendo as coisas de mão beijada (...) A participação não existe como gostaríamos que fosse, mas é um trabalho que tem que ser feito (Perfeccionista/Assessora Comunitária).

Contrário ao posicionamento acima, outros depoimentos apontam para as dificuldades e limitações internas das próprias equipes de profissionais e do Projeto como um todo:

Falta inserção real comunitária (...) principalmente pelos profissionais chamados técnicos, a proximidade com a comunidade é reduzida. Não só por parte dos técnicos, mas dos assessores comunitários também (...) chamar a comunidade pra dentro da raiz não é inserção comunitária. A equipe tem que estar na comunidade, nas escolas, associações, nos encontros informais. Tem que levar o trabalho para o meio da rua, ele não pode ser "engabinetado". A tendência dos profissionais técnicos é "engabinetar". Há um afastamento, encastelamento (...) Cerca de 50\% não está nem aí pro método, pra linha de atuação (...) é muito deficitário ainda a inserção comunitária do tipo freiriano (Idealista/Assessor Comunitário).

No entanto, deve ser levado em consideração avanços, principalmente no que diz respeito às diretrizes teórico-metodológicas, de interpretação e problematização da realidade comunitária, dispostas nos documentos e algumas vezes desenvolvidas pelas equipes.

A proposta do projeto está ligada a uma metodologia participativa e dialógica tanto no sentido de organização das equipes, que o planejamento seja feito por todos no sentido de equipe, de grupo, de não ser só alguém que pensa e outros executarem e no sentido de como essas ações vão ser realizadas sempre priorizando ser com a comunidade e não para a comunidade (...) A gente tem muita base em Paulo Freire e o próprio método que a gente tem que está discutindo mais com os profissionais para não parecer que se tem uma idéia e o que se efetiva é outra (Dialógica/Assistente Social).

Por fim, uma reflexão crítica em torno do Projeto Raízes de Cidadania torna-se fundamental para a percepção dos desafios da construção e consolidação de uma política pública que realmente atenda aos anseios das classes subalternas e caminhe rumo a uma efetiva participação popular, apontando para uma real democratização do poder público e a ampliação da esfera pública, elementos fundamentais no processo de transição socialista e construção de uma igualdade social plena. 


\section{CONSIDERAÇõES FINAIS}

Diante das informações coletadas através da pesquisa qualitativa e do aprofundamento da bibliografia utilizada, diversos elementos relacionados às fragilidades, limites e possibilidades da participação popular mediante o Projeto Raizes de Cidadania foram evidenciados.

Percebe-se a relevância de ações e discursos que reforçam o ideário neoliberal principalmente no que concerne a relação entre Sociedade civil e Estado. Há uma verdadeira investida na desmobilização e esvaziamento das lutas sociais, mediante, sobretudo, a busca de soluções negociadas entre empresariado e trabalhadores, associadas à implementação de políticas assistenciais a partir de programas emergenciais envolvendo a participação das organizações populares. 0 envolvimento popular na implementação das políticas sociais estatais não visa apenas a legitimidade do governo, como constitui uma medida voltada para a institucionalização do trabalho comunitário como alternativa para a redução dos custos no âmbito das políticas sociais (ABREU, 2002).

Os depoimentos coletados revelam, portanto, a fragilidade do processo de participação popular não apenas no Projeto Raízes de Cidadania, mas no âmbito municipal em geral.

É importante ressaltar que esta pesquisa não pretende deslegitimar algumas ações e políticas importantes desenvolvidas no âmbito do poder público local, tendo em vista seu caráter contraditório. É oportuno realizar algumas ponderações, como: faz-se necessário que o Projeto tenha em suas diretrizes uma maior clareza sobre a natureza de suas ações e sobre seus reais objetivos, bem como um aprofundamento das perspectivas teórico-metodológicas e éticopolíticas que devem orientar os trabalhos desenvolvidos pelos profissionais. Caso contrário, as práticas supostamente voltadas para a participação popular poderão continuar correndo o risco de se restringirem em meras técnicas e metodologias vazias de significados caindo no subjetivismo que dissocia a relação dialética entre objetividade e subjetividade, portanto, não contribuindo para o processo de real participação popular.

Os desafios postos nesta realidade são imensos. Dentre estes, o de estimular e potencializar experiências de participação popular não apenas para a efetivação de políticas públicas de caráter democrático, mas, sobretudo, na perspectiva de construção de uma contra-hegemonia orientada e conduzida pelas classes subalternas. 
Vale destacar que diante de um projeto político municipal democratizante e participativo de atuação conjunta entre Estado e sociedade, delineiam-se perspectivas ou projetos antagônicos onde se trava um verdadeiro campo de forças permeado por conflitos e contradições. Diante desta realidade, é de fundamental importância o acúmulo de forças sociais que contribuam para o desencadeamento de processos - local e global - consistentes e plenos de participação popular que caminhem junto a construção e o estabelecimento de uma nova ordem societária orientada para a emancipação humana.

\section{REFERÊNCIAS}

ABREU, Marina Maciel. Serviço Social e a organização da cultura: perfis pedagógicos da prática profissional. São Paulo: Cortez, 2002.

AMARAL, Ângela Santana do. A categoria Sociedade Civil na Tradição Liberal e Marxista. In: MOTA, Ana Elizabete (org.). O mito da Assistência: ensaios sobre Estado, política e sociedade. Recife: Ed. Universitária da UFPE, 2006.

ANTUNES, Ricardo. Adeus ao trabalho? Ensaio sobre as metamorfoses e a centralidade do mundo do trabalho .São Paulo: Cortez, $9^{\mathrm{a}}$ ed., 2003.

ARAÚJ0, Liana Brito de C. A questão do método em Marx e Lukács: o desafio da reprodução ideal de um processo real. In: MENEZES, Ana Maria Dorta de; FIGUEIRED0, Fábio Fonseca (orgs). Trabalbo, sociabilidade e educação: uma crítica à ordem do capital. Fortaleza: Ed. UFC, 2003. (Coleção Diálogos Intempestivos)

BARREIRA, Irlys Alencar Firmo. O reverso das vitrines: conflitos urbanos e cultura política em construção. Rio de Janeiro: Rio Fundo Ed., 1992.

BEHRING, Elaine Rossetti. Brasil em contra-reforma: desestruturação do Estado e perda de direitos. São Paulo: Cortez, 2003.

BORON, Atílio. A sociedade civil depois do dilúvio neoliberal. In: SADER, Emir; GENTILLE, Pablo (orgs). Pós-neoliberalismo: as políticas sociais e o Estado democrático. Rio de Janeiro: Paz e Terra, 1995.

. Os "novos Leviatãs" e a pólis democrática: neoliberalismo, decomposição estatal e decadência da democracia na América Latina. In: SADER, Emir; GENTILLE, Pablo (orgs). Pós-neoliberalismo II: que Estado para que democracia? 
Petrópolis: Vozes, 2004.

BRAVO, Maria Inês Souza. Gestão Democrática na Saúde: 0 potencial dos conselhos. In: BRAVO, Maria Inês Souza; PEREIRA, Potyara Amazoneida (orgs). Política Social e democracia. São Paulo: Cortez, 2001.

CAMPOS, Marta Silva. Democratização e desigualdade social no Brasil. Serviço Social \& Sociedade. Ano XIX, n. 57. São Paulo: Cortez, 1998.

CORREIA, Maria Valéria da Costa. A relação Estado/ Sociedade e o controle social: fundamentos para o debate. Serviço Social \& Sociedade. Ano XXIV, n. 77. São Paulo: Cortez, 2004.

DIAS, Edmundo. A liberdade (im) possivel na ordem do capital: reestruturação produtiva e passivização. São Paulo: IFCH/Unicamp, n. 29, 1997.

FREIRE, Paulo. Pedagogia da autonomia: saberes necessários à prática educativa. São Paulo: Paz e Terra, 29a ed., 2004 (Coleção Leitura).

.Política e educação: ensaios. São Paulo: Cortez, 2003. (Coleção questões da nossa época, v. 23).

FUNDAÇÃO DA CRIANÇA E DA FAMÍLIA CIDADÃ - Funci. Manual de Organização do Projeto Raízes de Cidadania. Fortaleza, 2006.

. Projeto Raízes de Cidadania. Fortaleza, 2007.

GRUPPI, Luciano. Tudo Começou com Maquiavel: as concepções de Estado em Marx, Engels, Lênin e Gramsci. Porto Alegre: L\&PM, 1996.

MARX, Karl. Introdução à Crítica da Economia Política. São Paulo: Martins Fontes, 2002. . Manuscritos Econômico-Filosóficos. São Paulo: Martin Claret, 2004.

MOTA, Myriam Becho. História: das cavernas ao Terceiro Milênio. São Paulo: Moderna, 1.ed., 1997.

NETTO, José Paulo. Democracia e transição socialista: escritos de teoria e política. Belo Horizonte: Oficina de Livros, 1990.

PAIVA, Beatriz Augusto de. 0 poder popular na Venezuela e a práxis bolivariana. In: OURIQUES, Nildo (org.). Raízes no Libertador: Bolivarianismo e poder popular na Venezuela. Florianópolis: Insular, $2^{a}$ ed. rev., 2005.

PEREIRA, Potyara Amazoneida. Estado, regulação social e controle democrático. In: BRAVO, Maria Inês Souza; PEREIRA, Potyara Amazoneida (orgs). Política 
social e democracia. São Paulo: Cortez, 2001.

PORTELLI, Hugues. Gramsci e o bloco bistórico. Trad. Angelina Peralva. Rio de Janeiro: Paz e Terra, $6^{a}$ ed., 2002.

Programa de Governo Municipal 2004 / Luizianne Lins 13 - Por Amor a Fortaleza: propostas para uma cidade bela, justa e democrática, agosto de 2004.

RIBEIR0, Sâmbara Paula Francelino. Parceria: os caminhos da relação entre o poder público estatal e as ONGs. Dissertação de Mestrado em Serviço Social. Recife: UFPE, 2000.

SIMIONATO, Ivete; NOGUEIRA, Vera Maria Ribeiro. Pobreza e Participação: o jogo das aparências e as armadilhas do discurso das agências multilaterais. Serviço Social \& Sociedade. Ano XXII, nº 66. São Paulo: Cortez Editora, 2001.

. Estado, sociedade civil e espaços públicos: uma análise do "Plano Plurianual" - 2004/2007. Serviço Social e Sociedade. Ano XXVII, n. 88. São Paulo: Cortez, 2006.

SOUSA, Maria Luiza de. Desenvolvimento de comunidade e participação. 7 ed. São Paulo: Cortez, 2000.

TEIXEIRA, Francisco José Soares. CIC: A "razão esclarecida" da FIEC. Propostas Alternativas, n. 4. Fortaleza: Cadernos de Ensaios do Instituto de Memória do Povo Cearense, 1995. 